\title{
Supplier Asset Allocation in a Pool-Based Electricity Market
}

\author{
Donghan Feng, Deqiang Gan, Jin Zhong, Member, IEEE, and Yixin Ni, Senior Member, IEEE
}

\begin{abstract}
A power supplier in a pool-based market needs to allocate his generation capacities to participate in contract and spot markets. In this paper, the optimal portfolio selection theory is introduced for this purpose. A model applying this theory is proposed to solve the supplier asset allocation problem. Real market data are used in a numerical study to test the proposed model. The results show that different asset allocation solutions can yield very different risk-return tradeoffs for a supplier, and the proposed method can be potentially useful in suppliers' decision making.
\end{abstract}

Index Terms-Assets allocation, electricity market, portfolio selection, risk management.

\section{INTRODUCTION}

W ITH the restructuring of the power industry, the formerly integrated electric power suppliers under regulation are transforming into independent generation companies (GenCos). Other results of the power system deregulation include the development of various energy markets and the diversification of bilateral exchanges. Nowadays, an electricity market is usually composed of a day-ahead energy market, a real-time energy market, and several contractual instruments, such as fixed forward, flexible forward, optional forward, contract for differences, and the like [1]-[6]. The diversity of trading types provides GenCos more options to sell their generation products in different markets. In these circumstances, GenCos are required to devise their own strategies on how to allocate generation proportions for different exchanges. This can be regarded as a portfolio selection problem. With an optimized portfolio, a GenCo can maximize its return while minimizing the corresponding risk.

In a deregulated environment, power suppliers as participants in highly volatile spot markets are required to consider market risks in their decision-making. Different aspects of risk management for power suppliers have been studied in [7]-[26]. The issues of problem modeling, contract pricing, and the effects of the contracts are discussed in [11]-[15]. The potential risks in generation investment and planning are discussed in [16] and [17]. The works in [18]-[20] address day-ahead bidding strategies and their associated risks. There are also a few publications that discuss the problem of supplier asset allocation [21]-[24].

Manuscript received September 20, 2005; revised December 21, 2006. This work was supported in part by a Young Investigator Award of Zhejiang Natural Science Foundation (Grant R503198). Paper no. TPWRS-00593-2005.

D. Feng and D. Gan are with the College of Electrical Engineering, Yuquan Campus, Zhejiang University, Hangzhou, China (e-mail: seedplayer@163.com; dgan@zju.edu.cn).

J. Zhong and Y. Ni are with the Department of Electrical and Electronic Engineering, University of Hong Kong, Hong Kong (e-mail: jzhong@eee.hku.hk; yxni@eee.hku.hk).

Digital Object Identifier 10.1109/TPWRS.2007.901282
Various tools have been applied for risk management. A graphic methodology is used in [21] for risk analysis. A simulation technique is proposed for the same purpose in [24]. A method based on the fuzzy set theory is described in [25]. In an optimization framework, risk could be modeled in the objective function or as one of the constraints. A popular approach is to include risk factors in the objective functions, as shown in [7], [18], [20], [23], and [26]. This approach will be applied by this paper.

We will introduce portfolio selection theory and propose a solution for the supplier asset allocation problem in this paper. In Section II, the framework of portfolio selection theory is described. In Section III, the background of supplier asset allocation is examined, and the special features of supplier asset allocation are discussed. In Section IV, mathematical models are established for asset allocation in the electricity market. After which, a case study based on the statistics of a real market (PJM) is performed in Section V. Finally, some conclusions are drawn in Section VI.

\section{Methodology for Portfolio Selection}

In this section, we will briefly describe the framework of portfolio selection theory. The latest developments of this theory can be found in [27] and [48].

Maximizing return and minimizing risk are the goals of investors. The reality is that it is usually difficult to achieve these two goals simultaneously. Therefore, investors are searching for trade-off solutions between return and risk. This process can be considered as utility maximization. Equation (1) formulates one of the utility functions that is commonly employed by financial theorists; this formula is also employed by the Association of Investment Management and Research (AIMR) [48]

$$
U=E-0.5 \cdot A \cdot R
$$

where $E$ denotes the expected return of the investor's portfolio, $R$ denotes the risk of the investor's portfolio, and $A$ denotes the investor's degree of risk aversion. Assume that the number of asset types available for the investor is $m$, the portfolio selection problem is to decide the share of each asset $s_{1}, s_{2}, \ldots, s_{m}$, so that the utility function $U=f\left(s_{1}, s_{2}, \ldots, s_{m}\right)$ can be maximized. The optimization problem can be formulated as follows:

$$
\begin{array}{ll}
\underset{s_{1}, s_{2}, \ldots, s_{m}}{\operatorname{Max}} & U=f\left(s_{1}, s_{2}, \ldots, s_{m}\right) \\
\text { S.T. } & \sum_{i=1}^{m} s_{i}=1 \\
& s_{i} \in[0,1], i=1,2, \ldots, m .
\end{array}
$$




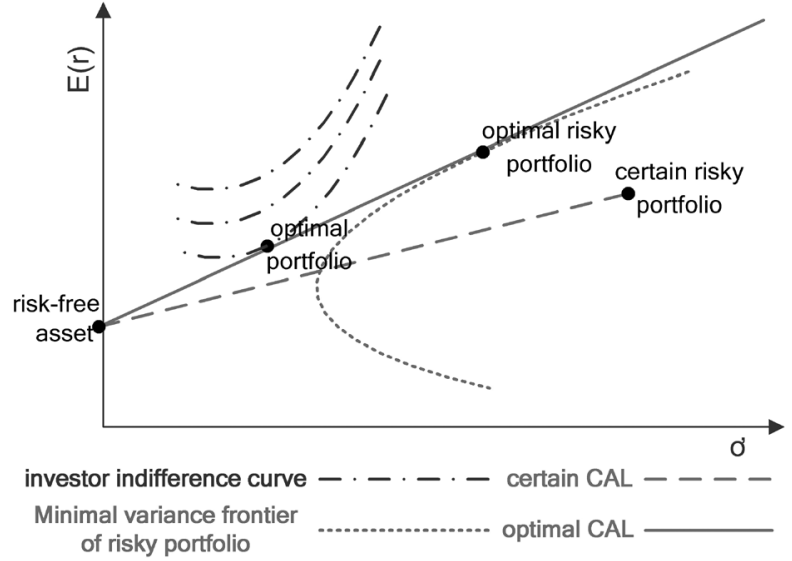

Fig. 1. Portfolio optimization state.

In general, the utility function $f\left(s_{1}, s_{2}, \ldots, s_{m}\right)$ is difficult to be formulated explicitly. To solve the problem, portfolio selection theory has developed a sophisticated method, which can be described in the five steps given below.

\section{A. Estimate the Return Characteristics in the Holding Period}

From an investor's viewpoint, the criterion to determine the share of a certain asset in his portfolio is based on the return of the asset in a future holding-period. However, the problem is that the holding-period return of some assets can be arbitrarily distributed because of some uncertainties, such as asset price volatilities. In the financial field, asset return is usually described as a random variable according to its statistic characteristics. For example, if asset $i$ has a return rate of $r_{i}$, the characteristics of $r_{i}$ can be measured by its expectation $E\left(r_{i}\right)$ and standard deviation $\sigma_{i}$, and the return characteristics between assets can be measured by covariance $\operatorname{cov}\left(r_{i}, r_{j}\right)$ or correlation coefficient $\rho_{i j}$.

\section{B. Find the Optimal Risky Portfolio}

Within all the assets that are available for investment, assume without loss of generality that there are $n$ assets whose return is not fixed. These assets are called risky assets. Variables $w_{1}, w_{2}, \ldots w_{n}$ are defined as the weights of risky assets in a risky asset portfolio.

In the $E-\sigma$ coordinates, the capital allocation line (CAL) is defined as a series of line segments that connect the point of risk-free asset and the points in the feasible risky asset combination set (risky portfolio opportunity set), as shown in Fig. 1. The optimal risky asset portfolio is on a certain CAL that has a maximum slope $K_{p}=\left[E\left(r_{p}\right)-r_{f}\right] / \sigma_{p}$, where $r_{f}$ is the return rate of risk-free asset and

$$
\begin{aligned}
E\left(r_{p}\right) & =\sum_{i=1}^{n} w_{i} E\left(r_{i}\right) \\
\sigma_{p}^{2} & =\sum_{i=1}^{n} \sum_{j=1}^{n} w_{i} w_{j} \operatorname{cov}\left(r_{i}, r_{j}\right) .
\end{aligned}
$$

Thus, the task of finding the optimal risky asset portfolio can be converted to an optimization problem of maximizing $K_{p}$. This problem can be formulated as

$$
\begin{array}{ll}
\max _{w_{1}, w_{2} \ldots, w_{n}} & \frac{\sum_{i=1}^{n} w_{i} E\left(r_{i}\right)-r_{\mathrm{f}}}{\sqrt{\sum_{i=1}^{n} \sum_{j=1}^{n} w_{i} w_{j} \operatorname{cov}\left(r_{i}, r_{j}\right)}} \\
\text { S.T. } & \sum_{i=1}^{n} w_{i}=1 \\
& w_{i} \in[0,1], i=1,2 \ldots, n .
\end{array}
$$

The optimal risky asset portfolio $w_{1}^{*}, w_{2}^{*}, \ldots, w_{n}^{*}$ can be found by solving the optimization problem defined above. Since objective function (4) is non-concave, model (4)-(6) is not a convex optimization problem, even though it has a nice polyhedral feasible region. In this paper, we will use a lifting technique to transform (4)-(6) into a convex quadratic programming problem that is equivalent to (4)-(6). Then the equivalent problem will be solved directly by convex quadratic programming techniques. The details of this solution procedure are well described in [49].

\section{Get the Return Characteristics of the Optimal Risky Asset Portfolio}

After we obtain the optimal risky asset portfolio $w_{1}^{*}, w_{2}^{*}, \ldots, w_{n}^{*}$, the return characteristics of the optimal risky asset portfolio, $E\left(r_{p}\right)^{*}$ and $\left(\sigma_{p}^{2}\right)^{*}$, can be easily formulated as in

$$
\begin{aligned}
E\left(r_{p}\right)^{*} & =\sum_{i=1}^{n} w_{i}^{*} E\left(r_{i}\right) \\
\left(\sigma_{p}^{2}\right)^{*} & =\sum_{i=1}^{n} \sum_{j=1}^{n} w_{i}^{*} w_{j}^{*} \operatorname{cov}\left(r_{i}, r_{j}\right) .
\end{aligned}
$$

\section{Determine the Share Between Risky Portfolio and Risk-Free Asset}

The share of risk portfolio $y^{*}$ and the share of risk-free asset $\left(1-y^{*}\right)$ can be obtained by solving the following:

$$
\begin{aligned}
\max _{y} U & =E\left(r_{c}\right)-0.5 A \sigma_{c}^{2} \\
& =r_{f}+y\left[E\left(r_{p}\right)^{*}-r_{f}\right]-0.5 A y^{2}\left(\sigma_{p}^{2}\right)^{*}
\end{aligned}
$$$$
\text { S.T. } \quad 0 \leq y \leq 1
$$

where $r_{c}$ denotes the return rate of the overall portfolio.

When the inequality constraint (9) is inactive, the optimal solution has an analytical form as shown in (10), which can be deduced from the first-order optimality condition

$$
y^{*}=\frac{E\left(r_{p}\right)^{*}-r_{f}}{A \cdot\left(\sigma_{p}^{2}\right)^{*}} .
$$


Formula (10) indicates that the share of risky portfolio is linear to the inverse of risk aversion degree. The return and the risk of overall portfolio are $r_{f}+y^{*} \cdot\left[E\left(r_{p}\right)^{*}-r_{f}\right]$ and $y^{* 2}\left(\sigma_{p}^{2}\right)^{*}$, respectively.

\section{E. Calculate the Share of Each Asset in the Portfolio}

The share of each risky asset $i$ and the share of the risk-free asset are given as follows:

$$
\begin{aligned}
& s_{i}^{*}=w_{i}^{*} y^{*}, \quad i=1,2 \ldots, n \\
& s_{f}^{*}=1-y^{*} .
\end{aligned}
$$

\section{DISCUSSION OF THE SUPPLIER ASSET ALLOCATION PROBLEM}

The portfolio selection methodology described in Section II is based on the applications in security markets. The asset allocation problem in electricity energy markets may have considerable differences with the portfolio selection problem in security markets. In security markets, an investor holds financial products, such as bonds, stocks, and currency, while in electricity markets, the fundamental assets are different types of electrical products like bilateral contracts, spot energy, and ancillary services. A power supplier could also invest in security markets using their money capital, but this is not our concern in this work. The asset allocation problem concerning both electricity markets and security markets is the topic of our current research.

The designs of existing electricity markets are rather different. However, a number of similarities can be observed. First, energy is the main product of electric power suppliers accounting for the majority in the trades [28]; therefore, we will consider only energy in this work and leave ancillary services for further development. Second, although a market can either be pool based or contract based, to a certain extent, it always supports contractual exchange. ${ }^{1}$ Third, a day-ahead or real-time market is essential for system operation [34]-[39].

There are many types of energy contracts in an electricity market, including callable/puttable flexible electricity contacts, one-way/two-way contracts for differences, fixed-price physical forward, and the like. In general, a contract can either be risky (such as a puttable flexible electricity contact) or risk-free (such as a two-way contract for differences).

Based on the above observations, in this study, we will focus on three types of assets: risk-free contracts, risky contracts, and day-ahead energy. Despite the diversities of actual market designs and contract forms, the portfolio selection methodology described in Section II is rather general.

In the rest of this section, we will explain the motivation of proposing a portfolio selection framework in this study, while alternatives such as real option models [45] are available.

\footnotetext{
${ }^{1}$ In the early stages of the electricity market in England and Wales, over $80 \%$ of electricity was traded through contract for difference market [29], and under NETA (New Electricity Trading Arrangements), 95\% of electricity was traded through bilateral contracts as of year 2003 [30]. Bilateral contracts account for $80 \%-85 \%$ of electricity exchange, and the day-ahead market accounts for $10 \%-15 \%$ in Poland electricity market [31]. In China, nearly $90 \%$ of electricity trade is through various contract markets [32]. In the USA, Commodity Exchange of New York (COMEX) started the exchange of electricity futures contracts in March 1996 [33].
}

For an utterly risk-averse investor, a real option-based approach may result in a different portfolio decision. The idea can be stated briefly as follows. When making decisions on a project (or real option), an investor can construct a portfolio whose payoffs can exactly replicate the payoffs of the project. If the project costs more than the portfolio, it is obviously unattractive. The investor can obtain the same payoffs more cheaply by buying the replicating portfolio. If the project costs less than this portfolio, it is obviously attractive. The investor can invest the project and sell the replicating portfolio and thereby lock-in in a certain profit.

In principle, this method is an optimal solution for an utterly risk-averse investor, while two assumptions are required for the realization of the method. One assumption is that the investigated market is a complete market, and the other assumption is that the investors always have sufficient cash to support the hedging operation. In most of the current electricity markets, these two assumptions are difficult to fulfill. There are few electricity markets that have mature financial markets for electricity products. Electricity futures do exist in some markets. However, the correlation between futures prices and spot prices is not good enough [42]-[44]; thus, a perfect hedging is absent. The second assumption is also too strong. Because of the large exchange quantities in the electricity market, some suppliers may not always have enough money to fulfill or maintain a complete hedging position. Moreover, for aggressive investors (investors with low risk-averse levels), they would like to invest their money in some high-risk, high-return assets rather than use the money for hedging. The reason is that the former operation will generate a higher return, although at the cost of high risk, but this is comparatively a minor factor, and the comprehensive utility will increase.

Generally speaking, the incompleteness of electricity financial markets and the practical constraints of electricity exchanges and power suppliers result in the invalidation of some "strong" methods. This gives way to Markowitz portfolio analysis in application.

\section{Modeling the Supplier Asset Allocation Problem}

Based on the discussions in the previous section, we will derive a mathematical model for power suppliers' asset allocation in this section.

\section{A. Supplier Model}

Assume that the cost function of a supplier during a trading interval is composed of two components: fixed cost $a$ and variable cost $\left(b \cdot G+c \cdot G^{2}\right)$, where $G$ denotes the scheduled energy generation in the trading interval

$$
C(G)=a+b \cdot G+c \cdot G^{2} .
$$

The risk aversion degree $A$ is the supplier's private information. Different suppliers choose different values of $A$ according to their capabilities of enduring risk and their attitudes toward risk. If $A<0$, the supplier is risk-loving; if $A=0$, the supplier is risk-neutral; and if $A>0$, the supplier is risk-averse. Generally speaking, risk-averters are predominant in most markets [47], [48]. 
The risk aversion degree $A$ can be estimated by means of a questionnaire-investigation [40]. Some scholars estimate $A$ to be $2 \sim 4$ in American investment markets (the readers are referred to a textbook on investment science). Since there is no authoritative data yet describing the risk preference of electricity suppliers, in order to find an appropriate $A$, the following principles are followed in this work.

1) $A$ should not cause an extremely low expected return.

2) $A$ should not cause an extremely high expected risk.

3) Both return and risk should not be too sensitive to $A$ (or a tiny change of attitude toward risk will cause a significant variation of return or risk, resulting in an unstable finance for the company).

Indeed, 1) and 2) are the aims of the so-called Enterprise Profit Management and Enterprise Risk Management, respectively. Based on the above principles, we choose $A$ to be a number between 2.89 and 6.1. Within this range, the expected return rate, the risk level, and the sensitivities of return and risk are appropriate. (A return- $A$ curve and a risk- $A$ curve can be referred to in Fig. 5.)

Another assumption in this work is that the day-ahead market is a perfectly competitive market, so the suppliers in the market are price-takers. Therefore, offering marginal cost is a reasonable assumption for a supplier's bidding strategy.

\section{B. Return Model for Risk-Free Contracts}

In financial markets, the investment costs associated with the current profits depend on the prices in the last period. However, this is not the case in electricity markets. The total cost of generation depends on the cost functions of individual generators and the amount of their generation outputs. In this paper, the return in a decision period is defined as (total revenue - total cost)/total cost. Here, we call this definition as the decision period return (DPR) to distinguish it from other return definitions.

Assume that the number of trading intervals in a decision period is $K$. If $p_{k}^{n e}$ and $P_{k}^{n e}$ denotes the negotiated price and negotiated generation, respectively, in the $k$ th trading interval; the decision period return of risk-free contracts $\left(D P R_{F C}\right)$ can be formulated as follows:

$$
D P R_{F C}=\frac{\sum_{k=1}^{K}\left[p_{k}^{n e} \cdot P_{k}^{n e}-\left(a+b \cdot P_{k}^{n e}+c \cdot P_{k}^{n e}\right)\right]}{\sum_{k=1}^{K}\left(a+b \cdot P_{k}^{n e}+c \cdot P_{k}^{n e^{2}}\right)} .
$$

Since both $p_{k}^{n e}$ and $P_{k}^{n e}$ are given, $D P R_{F C}$ is a constant. In a situation where more than one risk-free contract is available, a supplier will take just the contract that has the highest $D P R_{F C}$.

\section{Return Model of Day-Ahead Market}

According to the previous definitions, the decision period return of a day-ahead market $\left(D \widetilde{P} R_{D A}\right)$ can be formulated as follows:

$$
D \tilde{P} R_{D A}=\frac{\sum_{k=1}^{K}\left[\tilde{p}_{k}^{D A} \cdot P_{k}-\left(a+b \cdot P_{k}+c \cdot P_{k}^{2}\right)\right]}{\sum_{k=1}^{K}\left(a+b \cdot P_{k}+c \cdot P_{k}^{2}\right)}
$$

where $\tilde{p}_{k}^{D A}$ denotes the day-ahead market price at the $k$ th trading interval, $\tilde{p}_{k}^{D A}$ is a random variable whose expected distribution depends on the price forecasting, and $P_{k}$ denotes the generation scheduled in the $k$ th trading interval.

Then the expected return and variance of $D \tilde{P} R_{D A}$ can be formulated as follows:

$$
\begin{aligned}
\mathrm{E}\left(D \tilde{P} R_{D A}\right) & =\frac{\sum_{k} P_{k} \cdot \mathrm{E}\left(\tilde{p}_{k}^{D A}\right)}{\sum_{k}\left(a+b \cdot P_{k}+c \cdot P_{k}^{2}\right)}-1 \\
\sigma^{2}\left(D \tilde{P} R_{D A}\right) & =\frac{\sum_{k} P_{k}^{2} \cdot \sigma^{2}\left(\tilde{p}_{k}^{D A}\right)}{\left[\sum_{k}\left(a+b \cdot P_{k}+c \cdot P_{k}^{2}\right)\right]^{2}} .
\end{aligned}
$$

In (16) and (17), the estimation of $\mathrm{E}\left(\tilde{p}_{k}^{D A}\right)$ and $\sigma^{2}\left(\tilde{p}_{k}^{D A}\right)$ is a spot-price forecasting problem, which is a research field by itself. There are many methods for price forecasting. Since providing a sophisticated method for price forecasting is not the purpose of this paper, we will employ a simple historical data-based method for price forecasting. The sample of the spot price in the $k$ th trading interval consists of historical data in similar hours and months. ${ }^{2}$

It should be noted that there is a crucial presumption in using the mean-variance model in asset allocation. This assumption is each asset's return follows a normal distribution, so that asset returns can be portrayed only by their expected mean and expected variance. Therefore, before applying (16) and (17) to describe $D \widetilde{P} R_{D A}$, we need to know whether or not $D \widetilde{P} R_{D A}$ follows a normal distribution. For this purpose, Jarque-Bera distribution test [51] and Lilliefors distribution test [52] are performed. The test results show that the distribution of $D \widetilde{P} R_{D A}$ can be considered as a normal distribution, although not every $\tilde{p}_{k}^{D A}$ in the decision period follows a normal distribution. The reason is that in a certain decision period (say, March 2008), there are always some $\tilde{p}_{k}^{D A}$ whose sample distributions are similar, for example, the sample distribution at 9 A.M., March 6, 2008 and that at 9 A.M., March 7, 2008. Equation (15) shows that $D \widetilde{P} R_{D A}$ is linear to each $\tilde{p}_{k}^{D A}$ in the decision period. The Central Limit Theorem states that the linear combination of identically distributed independent random variables approaches normal distribution when the number of variables increases. Based on these observations, we believe that the similarly distributed $\tilde{p}_{k}^{D A}$ (though their own distributions may not be normal) contributes to the normality of $D \widetilde{P} R_{D A}$.

Take the PJM market data as an example. Assume that a GenCo has the historical data from year 1999 to 2004, and the decision period is April 2005. The trading interval of the PJM day-ahead market is one hour, so there are $24 * 30=720$ trading intervals in the decision period. For every trading interval, the adjusted historical day-ahead prices in similar hours and months form a sample pool. The test result is that Lilliefors test can

\footnotetext{
2"Similar hours" was chosen because of the daily fluctuation of electricity price, while "similar months" was chosen because of the seasonal fluctuation of electricity price. Besides, since the historical data used in this work are from year 1999 to 2004, the fluctuation between years should also be considered. Therefore, the historical data are not directly used as the sample data but adjusted by a ratio, which is calculated from the curve-fitting at year axis.
} 
TABLE I

DisTRIBUTION TESTS RESULTS

\begin{tabular}{|c|c|c|c|}
\hline & J-B test & $\begin{array}{c}\text { Lilliefors } \\
\text { test }\end{array}$ & $\begin{array}{c}\text { Lilliefors test statistic } \\
\text { (critical value is 0.0886) }\end{array}$ \\
\hline Best & 0 & 0 & 0.056291 \\
\hline Median & 1 & 1 & 0.10186 \\
\hline Worst & 1 & 1 & 0.17163 \\
\hline $\mathrm{DPR}_{\mathrm{DA}}$ & 0 & 0 & 0.074215 \\
\hline
\end{tabular}

reject $58.3 \%$ of the $\tilde{p}_{k}^{D A}$,s as normal distribution at $5 \%$ significance. However, the same $5 \%$ significance in Lilliefors test cannot reject this one-month $D \widetilde{P} R_{D A}$ as a normal distribution.

More detailed results are provided in Table I. In this table, the Lilliefors test results are given. The number "1" indicates that the test can reject the null hypothesis (random variable follows a normal distribution), and "0" indicates that the test cannot reject the null hypothesis. Jarque-Bera test has also been performed, and the result is the same as that in Lilliefors test. These two types of distribution tests are performed at the 5\% significance level. The last column of this table lists the values of the Lilliefors test statistic (LTS). This is a measure of the approximation error to a normal distribution, in which the lower the value, the better the approximation of the sample to a normal distribution. Since there are $720 \tilde{p}_{k}^{D A}$,s in this example, it is inappropriate to list all the test results in this paper. Therefore, in Table I, we choose three representatives from the 720 random variables to demonstrate a view of the samples. They are the best, the median, and the worst (approximation to normal distribution) from all the 720 samples (every sample includes 100 sample points), which have the minimal, median, and maximal LTS, respectively. It is found that $D \widetilde{P} R_{D A}$ can be accepted by both the Jarque-Bera test and Lilliefors test, while the median $\tilde{p}_{k}^{D A}$ is rejected by both tests. The LTS of $D \widetilde{P} R_{D A}$ is between the best $\tilde{p}_{k}^{D A}$ and the median $\tilde{p}_{k}^{D A}$.

To further demonstrate the normality improvement of $D \widetilde{P} R_{D A}$, the distribution of $D \widetilde{P} R_{D A}$ and the median $\tilde{p}_{k}^{D A}$ are depicted in Figs. 2 and 3. These two figures show that both random variables seem normally distributed, while median $\tilde{p}_{k}^{D A}$ has a more severe "narrow peak-heavy tail" characteristic, which is the main reason why it is rejected by distribution tests. It should be pointed out that although accepted by both the Jarque-Bera and Lilliefors tests, $D \widetilde{P} R_{D A}$ also has the "narrow peak-heavy tail" characteristic to a certain degree, which is shown in Fig. 3. A Kurtosis improvement (from 3.4150 to 3.0282) also indicates an alleviation of the "narrow peak-heavy tail" characteristic. (The kurtosis of normal distribution is 3.)

\section{Return Model of Risky Contracts}

A supplier could have more than one risky contract in a portfolio. If there are $m$ types of risky contracts in a market, we should formulate $m$ models for these $m$ assets and combine them with the day-ahead asset to form a risky portfolio opportunity set. There is no theoretical difficulty in dealing with multiple risky contracts as shown in Section II. For simplicity, however, this paper considers only one typical risky contract form,

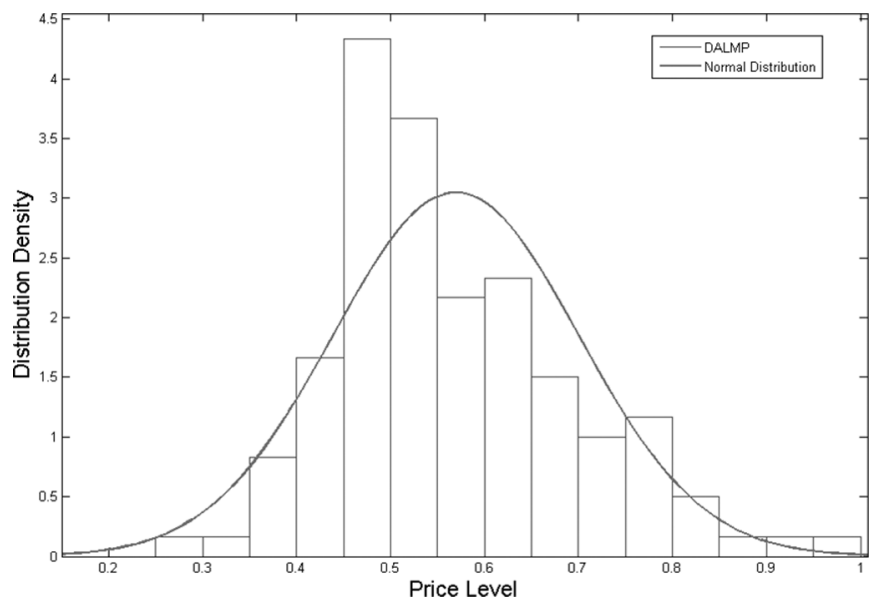

Fig. 2. Distribution of the $\tilde{p}_{k}^{D A}$ with median Lilliefors test statistics in the decision period, Kurtosis $=3.4150$.

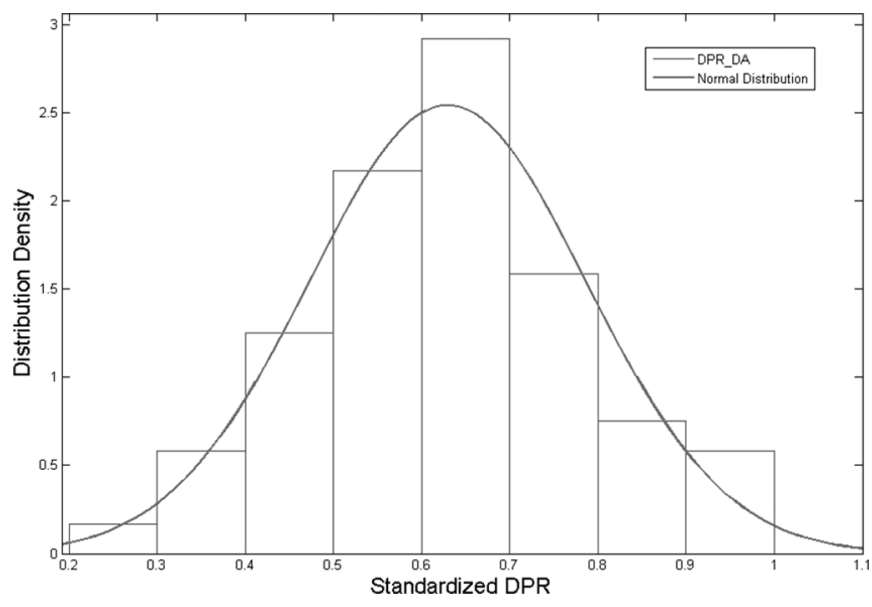

Fig. 3. Distribution of $D \widetilde{P} R_{D A}$, Kurtosis $=3.0282$.

namely, the interruptible contract between a supplier and the system operator.

As electric power cannot be efficiently stored, the system operator should maintain a balance between supply and demand at every instance of time. However, power demand varies from time to time for various reasons. When a severe imbalance happens, there is a need for the system operator to interrupt load or reduce generation if other favorable solutions are unavailable. Interruptible contracts are subscribed by the system operator in advance for this purpose. The interruptible contract that we consider in this paper is specified as follows:

$$
p_{R C}=\left\{\begin{array}{lll}
p_{a} & , & \tilde{p}^{D A} \geq p_{I} \\
p_{c} & , & \tilde{p}^{D A}<p_{I}
\end{array} .\right.
$$

Equation (18) indicates that when spot price $\tilde{p}^{D A}$ is higher than interruptible price $p_{I}$, the contract price $p_{R C}$ is equal to agreement price $p_{a}$; when the spot price is lower than the interruptible price, generation will be interrupted and a compensation price $p_{c}$ will be paid. If $p_{c}=0$, this contract becomes a non-compensated interruptible contract. The decision period return of this interruptible contract can be formulated as in (19) at 
the bottom of the page, where $\operatorname{Prob}(\bullet)$ is a probability function that denotes the probability that a random event will happen.

Now, let us investigate the distribution of $D \tilde{P} R_{R C}$. As the discussion in the previous subsection (Section IV-C) has pointed out, electricity prices have daily fluctuations and seasonal fluctuations. In a decision period (say, March-September 2008), some intervals are similar (such as 9 A.M., March 6, 2008 and 9 A.M., March 7, 2008), and some are significantly different (such as 1 A.M., March 6, 2008 and 9 A.M., March 7, 2008) from the aspect of price forecasting. Based on this standpoint, if we pick up the similar intervals in the decision period to form a group, then it is reasonable to assume that the $\tilde{p}_{k}^{D A}$ 's in the same group follow a similar distribution. Therefore, each interval in a certain group can be considered as a single Bernoulli trial (where the result is $p_{R C}=p_{c}$ with the probability $\tilde{p}^{D A}<p_{I}$ and $p_{R C}=p_{a}$ with the probability $\tilde{p}^{D A} \geq p_{I}$ ). Then the number of interruptions in the $m^{\text {th }}$ group $\tilde{X}_{m}$ will follow a binomial distribution, as shown in the following:

$$
\begin{aligned}
\operatorname{Prob}\left(\tilde{X}_{m}=k\right)=\left(\begin{array}{c}
N_{m} \\
k
\end{array}\right) \cdot \operatorname{Prob}\left(\tilde{p}_{m}^{D A}<p_{I}\right)^{k} \\
\cdot \operatorname{Prob}\left(\tilde{p}_{m}^{D A} \geq p_{I}\right)^{N_{m}-k}, \quad k=0,1, \ldots, N_{m}
\end{aligned}
$$

where $N_{m}$ denotes the number of trading intervals in the $m$ th group.

Therefore, the decision period return of a risky contract can be formulated as in (21) at the bottom of the page.

Equation (21) can be further expressed as a function of random variables $\tilde{X}_{1}, \tilde{X}_{2}, \ldots, \tilde{X}_{M}$, as shown in (22) at the bottom of the page.
The De Moivre-Laplace theorem states that a binomial distributed random variable will approach a normal distribution when the times of the Bernoulli trial increase. Since $N_{m}$ is a large number, we conjecture that $\tilde{X}_{m}$ will be close to a normal distribution.

Then let us take a closer look at (22). The denominator of (22) is approximately a constant because $\tilde{X}_{m}$ is a small number compared with $N_{m}$. On the other hand, the numerator of (22) is a linear combination of $\tilde{X}_{1}, \tilde{X}_{2}, \ldots, \tilde{X}_{M}$. Hence, we conjecture that $D \tilde{P} R_{R C}$ is close to a normal distribution. The reason is that when each $\tilde{X}_{m}$ follows a normal distribution, the $D \tilde{P} R_{R C}$ will also follow a normal distribution since a linear combination of normally distributed random variables still follows a normal distribution.

The above conjectures about $\tilde{X}_{m}$ and $D \tilde{P} R_{R C}$ are supported by distribution tests. In our tests, each $\tilde{X}_{m}$ sample pool consists of $N_{m}$ observations of comparison between $p_{I}$ and randomly selected day-ahead prices in similar hours and months from the adjusted PJM historical prices. A total of 1000 sample pools are used in the tests. The 5\%-significance Lilliefors tests accept $97.3 \%$ of these samples as normally distributed. In the test for $D \tilde{P} R_{R C}$, the acceptation rate is $96.1 \%$ in a pool of 1000 samples randomly simulated from adjusted PJM historical data. The median of the test data is 0.0673 of $\tilde{X}_{m}$ and 0.0715 of $D \tilde{P} R_{R C}$, which is significantly less than the critical value 0.0886 of the test.

\section{NUMERICAL STUDY}

The numerical study reported in this section is based on the PJM market data. We assume that a supplier is seeking for an

$$
D \tilde{P} R_{R C}=\frac{\sum_{k=1}^{K}\left[p_{a} \cdot P_{k}-\left(a+b \cdot P_{k}+c \cdot P_{k}^{2}\right)\right] \cdot \operatorname{Prob}\left(\tilde{p}_{k}^{D A} \geq p_{I}\right)+\left(p_{c} \cdot P_{k}-a\right) \cdot \operatorname{Prob}\left(\tilde{p}_{k}^{D A}<p_{I}\right)}{\sum_{k=1}^{K}\left(a+b \cdot P_{k}+c \cdot P_{k}^{2}\right) \cdot \operatorname{Prob}\left(\tilde{p}_{k}^{D A} \geq p_{I}\right)+a \cdot \operatorname{Prob}\left(\tilde{p}_{k}^{D A}<p_{I}\right)}
$$

$$
D \tilde{P} R_{R C}=\frac{\sum_{m=1}^{M}\left[p_{a} \cdot P_{m}-\left(a+b \cdot P_{m}+c \cdot P_{m}^{2}\right)\right] \cdot\left(N_{m}-\tilde{X}_{m}\right)+\left(p_{c} \cdot P_{m}-a\right) \cdot \tilde{X}_{m}}{\sum_{m=1}^{M}\left(a+b \cdot P_{m}+c \cdot P_{m}^{2}\right) \cdot\left(N_{m}-\tilde{X}_{m}\right)+a \cdot \tilde{X}_{m}}
$$

$$
\begin{aligned}
D \tilde{P} R_{R C} & =\mathrm{g}\left(\tilde{X}_{1}, \tilde{X}_{2}, \ldots, \tilde{X}_{M}\right) \\
& =\frac{\sum_{m=1}^{M}\left(p_{a} P_{m}-a-b P_{m}-c P_{m}^{2}\right) \cdot N_{m}+\left(p_{c} P_{m}-p_{a} P_{m}+b P_{m}+c P_{m}^{2}\right) \cdot \tilde{X}_{m}}{\sum_{m=1}^{M}\left(a+b P_{m}+c P_{m}^{2}\right) \cdot N_{m}-\left(b P_{m}+c P_{m}^{2}\right) \cdot \tilde{X}_{m}}
\end{aligned}
$$


TABLE II

INFORMATION HOLD BY SUPPLIER

\begin{tabular}{|c|c|c|c|}
\hline \multicolumn{2}{|c|}{ Private information } & \multicolumn{2}{c|}{ Public information } \\
\hline \multirow{2}{*}{ Total cost (\$) } & $\begin{array}{c}\mathrm{a}=1108 ; \\
\mathrm{b}=35.69 ; \\
\mathrm{c}=0.02081 ;\end{array}$ & $\begin{array}{c}\text { Day-ahead \& } \\
\text { Real-time } \\
\text { market price }\end{array}$ & $\begin{array}{c}\text { PJM Western Hub } \\
\text { DALMP \& RTLMP } \\
1999---2004\end{array}$ \\
\hline Risk aversion & 5 & $\begin{array}{c}\text { Risk-free } \\
\text { contract } \\
\text { degree }\end{array}$ & $\begin{array}{c}\text { (\$/MWh) } \\
\text { Scheduled }\end{array}$ \\
generation (MW) & 187 & $\begin{array}{c}\text { Risky contract } \\
(\$ / \mathrm{MWh})\end{array}$ & 46.2 \\
\hline
\end{tabular}

TABLE III

RETURN CHARACTERISTICS OF ASSETS

\begin{tabular}{ccc}
\hline Measuret & DPR expectation & $\begin{array}{c}\text { DPR standard } \\
\text { deviation }\end{array}$ \\
\hline DA(day-ahead market) & $2.09 \%$ & $4.75 \%$ \\
RC(risky contract) & $1.53 \%$ & $0.41 \%$ \\
FC(risk-free contract) & $1.5 \%$ & 0 \\
\hline
\end{tabular}

(The estimated correlation between the return-rates of DA and $\mathrm{RC}$ is 0.66225 .)

TABLE IV

PORTFOLIO: SHARE AND QUANTITY OF EACH ASSET

\begin{tabular}{lcc}
\hline Asset & Asset proportion & Asset quantity (MW) \\
\hline DA & $51.88 \%$ & 204.41 \\
RC & $6.01 \%$ & 23.68 \\
FC & $42.11 \%$ & 165.91 \\
\hline
\end{tabular}

asset allocation solution for the period of April 2005, and the supplier will base his decision on the historical PJM market data from 1999 to 2004, which are available on the PJM website. Assume that the supplier has two 197-MW fossil generators located at PJM Western Hub. The parameters of these generators are given in [41]. The cost information is listed in Table II. (The investment recovery rate is also accounted in the fixed cost.) Some other information required for the numerical study is also included in Table II.

First, based on historical data and the return models in Section IV, the statistical characteristics of the assets' returns in the decision period are estimated. The results are listed in Table III. Then by performing the procedure in Section II, the optimal asset allocation solutions are obtained and listed in Table IV.

The above is a simple example of asset allocation based on the optimal portfolio selection theory. A number of questions may rise immediately. First, some parameters in this method are obtained through statistical estimation; then although this method could theoretically yield an optimal portfolio solution, because of the deviation between reality and estimation, the

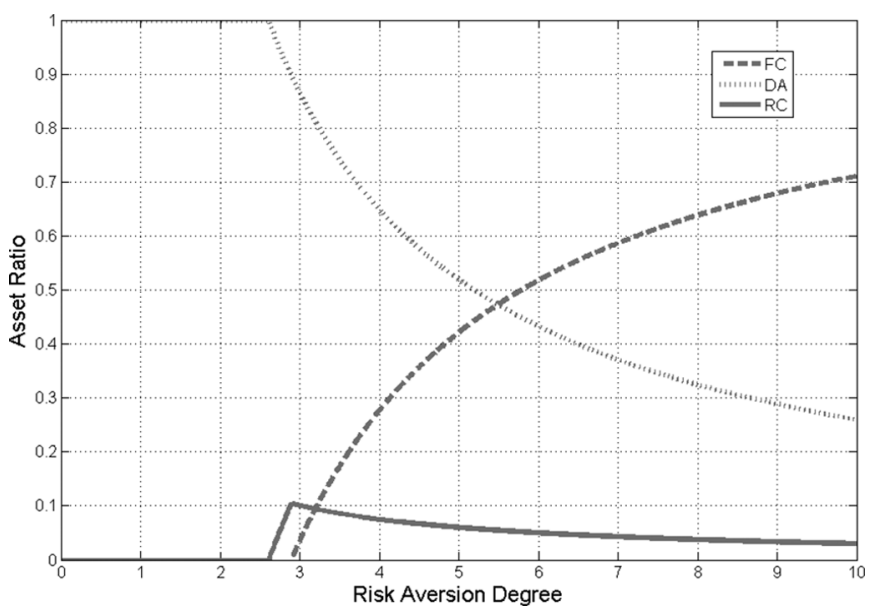

Fig. 4. Portfolio versus risk aversion.

portfolio computed by the proposed method is in fact not optimal. What will happen then if the supplier implements the portfolio? Second, how much better is the portfolio compared with other portfolios, such as a portfolio decided by a passive investment strategy? In other words, is the proposed optimal asset allocation method meaningful in reality? Third, how will this method perform in different situations, such as when a supplier's attitude toward risk changes?

In order to answer the above questions and test the proposed method further, additional simulations have been performed. First, we compute optimal portfolios when the supplier has different risk-aversion-degrees. The results are illustrated in Fig. 4.

Fig. 4 shows that the optimal portfolio performs piecewise when the supplier's risk-aversion-degree increases. When the risk-aversion-degree ranges from 0 to 2.61 , the optimal portfolio consists of only the day-ahead (DA) asset. This phenomenon indicates that when a supplier is with an extremely low risk aversion rate, he is more concerned about return than risk. Therefore, the optimal strategy is simply to choose the asset with the highest return, even though this asset may also have the highest risk. When the risk-aversion-degree ranges from 2.61 to 2.89 , the optimal portfolio consists of two assets, DA and risky contract (RC). This indicates that when the aversion rate is moderately low, the optimal strategy is to introduce the asset with moderate risk and return (RC) to adjust the portfolio risk. When the risk-aversion-degree is higher than 2.89 , the optimal portfolio consists of three assets: DA, RC, and risk-free contract (FC). This indicates that when the aversion rate becomes higher, increasing the ratio of RC alone cannot satisfy the need of mitigating the portfolio risk, and the optimal strategy is to further introduce risk-free asset FC (though its return is low). In this range, the ratio of risk-free asset performs a monotonous increase, while the ratios of the two risky assets perform a monotonous decrease as the risk-aversion-degree increases.

In Fig. 5, it is shown that when the risk-aversion-degree is lower than 2.61, the portfolio does not change (solely consists of DA asset), so that the return and risk are kept constant. When the risk-aversion-degree is higher than 2.61, both return and risk perform a monotonous decrease as the risk-aversion-degree increases. This tendency can be easily understood as follows: the 


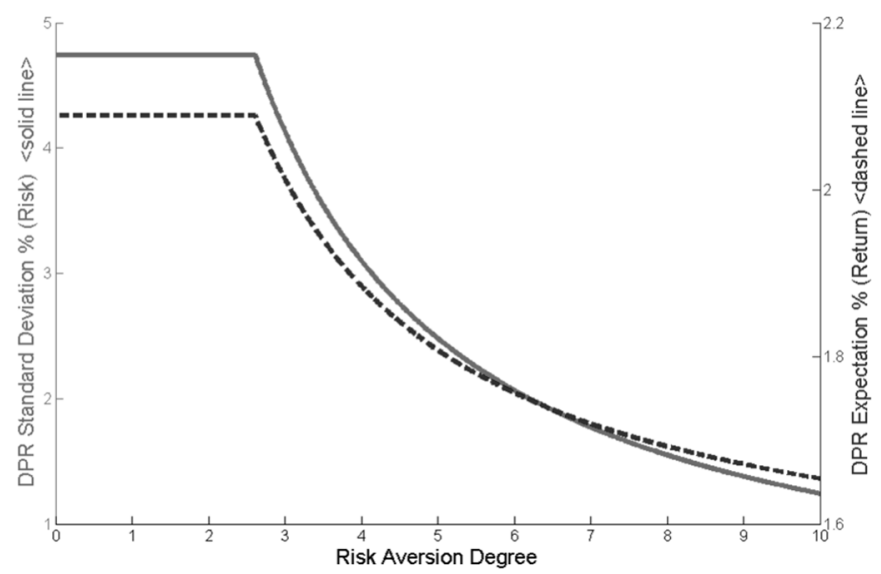

Fig. 5. Return characteristics versus risk aversion degree.

TABLE V

ACCOUNTING COMPARISON BETWEEN DifFERENT STRATEGIES

\begin{tabular}{|c|c|c|c|c|c|}
\hline Portfolio & $\begin{array}{c}\text { Measure } \\
\text { revenue } \\
(\mathrm{M} \$)\end{array}$ & $\begin{array}{c}\text { Actual } \\
\text { revenue } \\
(\mathrm{M} \$)\end{array}$ & $\begin{array}{c}\text { Revenue } \\
\text { estimation } \\
\text { error }\end{array}$ & $\begin{array}{c}\text { Expected } \\
\text { standard } \\
\text { deviation }\end{array}$ & $\begin{array}{c}\text { Actual } \\
\text { VaR (K\$) }\end{array}$ \\
\hline $\begin{array}{c}\text { Invest all assets in } \\
\text { day-ahead market }\end{array}$ & 6.2591 & 6.3303 & $1.12 \%$ & $4.75 \%$ & 8.5154 \\
\hline $\begin{array}{c}\text { Invest all assets in } \\
\text { risky contract }\end{array}$ & 6.2251 & 6.2495 & $0.39 \%$ & $0.41 \%$ & 1.1081 \\
\hline $\begin{array}{c}\text { Invest all assets in } \\
\text { risk-free contract }\end{array}$ & 6.2231 & 6.2231 & 0 & 0 & 0 \\
\hline $\begin{array}{c}\text { Proposed portfolio } \\
(\mathrm{A}=5)\end{array}$ & 6.2419 & 6.2803 & $0.61 \%$ & $2.48 \%$ & 4.4305 \\
\hline
\end{tabular}

portfolio with a higher risk-aversion-degree has a stronger motivation to bring down the risk. The portfolio mitigates its risk by adjusting the ratio of each asset, as the former paragraph and Fig. 4 show, by first introducing the asset with moderate risk and return $(\mathrm{RC})$, and if insufficient, further introducing the risk-free asset (FC). We can also notice from Fig. 5 that the return also performs a monotonous decrease as the risk decreases. This is because the mitigating risk is not for free but is at the cost of a lower return. Therefore, return performs decrease as risk decreases. Indeed, the proposed method is based on a compromise between the portfolio risk and the portfolio return.

Table $\mathrm{V}$ provides a performance comparison between different portfolios. The results show that the proposed method is seeking for an optimal balance between return and risk. The actual revenue column is calculated from the actual market data (PJM DALMP 2005), indicating the total portfolio revenue in the decision period if the proposed portfolio solution is applied. The expected revenue column lists the estimation values based on the historical data (PJM DALMP 1999-2004). The revenue estimation error column gives the estimation errors between the expected revenues and the actual ones. The errors estimated according to year 2005 data are within $1.5 \%$. The errors look acceptable based on this year's data.
The expected standard deviation column measures the portfolio risk; for comparison, we need a measure of the actual risk. Because the actual decision period return is a fixed value, we employ the value at risk (VaR) of cash flow at every trading interval in the decision period to measure the actual risk experience. ${ }^{3}$ The last two columns show that the portfolio with a high expected standard deviation also encounters high VaR in reality. According to the comparison between estimation and reality, we believe that if the proposed method is applied in an actual situation, the outcome will be close to what we had anticipated.

Diversification is a well-known strategy for reducing the nonsystematic risks in stock markets. Previous simulations and discussions in this section show that diversification is also an efficient approach to reduce electricity suppliers' risks. It is shown in Fig. 4 that suppliers with moderate and high risk-aversion-degrees have the optimal positions of holding a portfolio with all the three assets. However, we have to point out that diversification is constrained by some unique attributes of electricity markets. First, the category of assets is very limited in electricity markets compared with stock markets. Second, the correlations between the assets' returns are much closer in electricity markets than in stock markets. Asset returns are closely correlated because the prices of different electric exchanges are closely correlated. As generally recognized, the prices of day-ahead energy, real-time energy, and operational reserve are all high-correlated. Indeed, there is a lack of negative-correlated or even low-correlated assets in the electricity market. Therefore, it is very important for electricity suppliers to invest in other markets (e.g., financial markets such as stock market, futures market, and options market) to reduce the systematic risk in electricity markets. The strategy of investing in both electricity assets and financial assets is the topic of our current research.

\section{CONCLUSIONS}

An asset allocation strategy has a significant impact on an electricity supplier's future profits and potential risks. An optimal asset allocation strategy based on the portfolio selection theory is proposed in this paper. A numerical example based on the PJM market data is provided to demonstrate the application of the introduced theory. The results show that the portfolio selection theory is an elegant and potentially useful tool for managing the risks of electricity market suppliers. Further research is underway to expand the modeling capability of the suggested approach.

\section{REFERENCES}

[1] M. Shahidehpour, H. Yamin, and Z. Li, Market Operations in Electric Power Systems. New York: Wiley, 2002.

[2] T. W. Gedra, "Optional forward contracts for electric markets," IEEE Trans. Power Syst., vol. 9, no. 4, pp. 1766-1773, Nov. 1994.

${ }^{3} V a R$ is defined as $\operatorname{Prob}(\triangle$ Loss $<V a R) \leq 1-c$, where $\operatorname{Prob}(\bullet)$ denotes conditional probability function, $\Delta$ Loss denotes the loss of a portfolio in a decision period, and $c$ denotes the confidence level (set as 95\%). According to a certain investing strategy $s_{1}, s_{2}, \ldots, s_{m}$, in every trading interval $k$, there is a revenue $\left(\sum_{i-1}^{m} s^{i} \cdot p_{k}^{i} \cdot P_{k}\right)$ and a cost $\left(a+b \cdot P_{k}+c \cdot P_{k}^{2}\right)$; if the revenue is greater than the cost, then the cash flow is positive in this trading interval, and the cash flow is negative if the revenue is smaller than cost. For example, the actual VaR here equals to $4.4305 \mathrm{~K} \$$, which means that only $5 \%$ of the interval cash flows loses more than $4.4305 \mathrm{~K} \$$. 
[3] T. S. Chung, S. H. Zhang, C. W. Yu, and K. P. Wong, "Electricity market risk management using forward contracts with bilateral options," Proc. Inst. Elect. Eng., Gen., Transm., Distrib., vol. 150, no. 5, pp. 588-594, Sep. 2003.

[4] S. Oren, "Integrating real and financial options in demand-side electricity contracts," Decision Support Syst., vol. 30, no. 3, pp. 279-288, 2001.

[5] H. Niu, R. Baldick, and G. Zhu, "Supply function equilibrium bidding strategies with fixed forward contracts," IEEE Trans. Power Syst., vol. 20, no. 4, pp. 1859-1867, Nov. 2005.

[6] S. Palamarchuk, "Forward contracts for electricity and their correlation with spot markets," in Proc. IEEE Bologna PowerTech Conf., Bologna, Italy, Jun. 23-26, 2003.

[7] I. Vehvilainen and J. Keppo, "Managing electricity market price risk," Eur. J. Oper. Res., vol. 145, no. 1, pp. 136-147, Feb. 2003.

[8] R. Dahlgren, C. C. Liu, and J. Lawarree, "Risk assessment in energy trading," IEEE Trans. Power Syst., vol. 18, no. 2, pp. 503-511, May 2003.

[9] M. Denton, A. Palmer, R. Masiello, and P. Skantze, "Managing market risk in energy," IEEE Trans. Power Syst., vol. 18, no. 2, pp. 494-502, May 2003

[10] R. Bjorgan, C. C. Liu, and J. Lawarree, "Financial risk management in a competitive electricity market," IEEE Trans. Power Syst., vol. 14, no. 4, pp. 1285-1291, Nov. 1999.

[11] R. J. Kaye, H. R. Outhred, and C. H. Bannister, "Forward contracts for the operation of an electricity industry under spot pricing," IEEE Trans. Power Syst., vol. 5, no. 1, pp. 46-52, Feb. 1990.

[12] X. Zhang, X. Wang, and Y. H. Song, "Modeling and pricing of block flexible electricity contracts," IEEE Trans. Power Syst., vol. 18, no. 4, pp. 1382-1388, Nov. 2003.

[13] R. Bjorgan, H. Song, C. C. Liu, and R. Dahlgren, "Pricing flexible electricity contracts," IEEE Trans. Power Syst., vol. 15, no. 2, pp. 477-482, May 2000.

[14] T. S. Chung, S. H. Zhang, C. W. Yu, and K. P. Wong, "Electricity market risk management using forward contracts with bilateral options," Proc. Inst. Elect. Eng., Gen., Transm., Distrib., vol. 150, no. 5, pp. 588-594, Sep. 2003.

[15] T. W. Gedra, "Optional forward contracts for electric power markets," IEEE Trans. Power Syst., vol. 9, no. 4, pp. 1766-1773, Nov. 1994.

[16] C. J. Andrews, "Evaluating risk management strategies in resource planning," IEEE Trans. Power Syst., vol. 10, no. 1, pp. 420-426, Feb. 1995.

[17] H. Dai, F. F. Wu, and Y. Ni, "A comprehensive framework for evaluating nonutility generation projects," in Proc. IEEE Power Eng. Soc. Winter Meeting, Singapore, Feb. 2000, vol. 2, pp. 1040-1045.

[18] A. J. Conejo, F. J. Nogales, J. M. Arroyo, and R. Garcia-Bertrand, "Risk-constrained self-scheduling of a thermal power producer," IEEE Trans. Power Syst., vol. 19, no. 3, pp. 1569-1574, Aug. 2004.

[19] X. Chen, Y. He, Y. H. Song, Y. Nakanishic, C. Nakanishic, S. Takahashic, and Y. Sekine, "Study of impacts of physical contracts and financial contracts on bidding strategies of GENCOs," Int. J. Elect. Power Energy Syst., vol. 26, pp. 715-723, 2004.

[20] X. Ma, F. Wen, Y. Ni, and J. Liu, "Towards the development of risk-constrained optimal bidding strategies for generation companies in electricity markets," Elect. Power Syst. Res., vol. 73, pp. 305-312, 2005.

[21] R. A. Campo, "Probabilistic optimality in long-term energy sales," IEEE Trans. Power Syst., vol. 17, no. 2, pp. 237-242, May 2002.

[22] G. N. Bathurst, J. Weatherill, and G. Strbac, "Trading wind generation in short term energy markets," IEEE Trans. Power Syst., vol. 17, no. 3, pp. 782-789, Aug. 2002.

[23] M. Liu, F. F. Wu, and Y. Ni, "Market allocation between bilateral contracts and spot market without financial transmission rights," in Proc. IEEE Power Eng. Soc. Summer Meeting, 2003, vol. 2, pp. 13-17.

[24] B. Mo, A. Gjelsvik, and A. Grundt, "Integrated risk management of hydro power schedule and contract management," IEEE Trans. Power Syst., vol. 16, no. 2, pp. 216-221, May 2001.

[25] A. Schmutz, E. Gnansounou, and G. Sarlos, "Economic performance of contracts in electricity markets: A fuzzy and multiple criteria approach," IEEE Trans. Power Syst., vol. 17, no. 4, pp. 966-973, Nov. 2002.

[26] F. Li, M. Gabb, C. Aldridge, C. Cheung, R. Walker, G. Williams, and M. Bradley, "An optimal constraint management program for new electricity trading arrangements in the UK," in Proc. 14th Power System Computation Conf., Sevilla, Spain, Jun. 2002.

[27] H. Markowitz, Portfolio Selection-Efficient Diversification of Investments, 2nd ed. Malden, MA: Blackwell, 1997.
[28] B. Kranz, R. Pike, and E. Hirst, Integrated Electricity Markets in New York: Day-Ahead and Real-Time Markets for Energy, Ancillary Services, and Transmission, New York Independent System Operator. Schenectady, NY, Nov. 2002. [Online]. Available: http://www.nyiso. com.

[29] D. T. Y. Cheng, "Economic analysis of the electricity. Market in England and Wales," IEEE Power Eng. Rev., vol. 19, no. 4, pp. 57-59, Apr. 1999.

[30] S. Hesmondhalg, "Is NETA the blueprint for wholesale electricity trading arrangements of the future?," IEEE Trans. Power Syst., vol. 18 , no. 2, pp. 548-554, May 2003.

[31] W. Mielczarski, The Electricity Market in Poland-Recent Advances. Power Economics, Feb. 2002. [Online]. Available: http://www.findarticles.com/p/articles/mi_qa3888/is_200202/ai_n9031235.

[32] F. Zhu, L. Yang, B. Fan, X. Wei, and D. Gan, "East China power market development and trial operation," in Proc. IEEE Power Eng. Soc. General Meeting, San Francisco, CA, Jun. 2005, panel session summary.

[33] E. Tanlapco, J. Lawarree, and C. C. Liu, "Hedging with futures contracts in a deregulated electricity industry," IEEE Trans. Power Syst., vol. 17, no. 3, pp. 577-582, August 2002.

[34] PJMRTO Market Monitoring Unit, PJM 2003 State of the Market Report, March 4, 2004. [Online]. Available: http://www.pjm.com.

[35] Potomac Economics, Ltd., 2003 State of the Market Report-New York ISO, May 2004. [Online]. Available: http://www.nyiso.com.

[36] ISO New England, Inc., 2003 Annual Markets Report, 2004. [Online]. Available: http://www.iso-ne.com.

[37] F. Barrett, "CHP and the wholesale electricity market," in Proc. 94th Anпи. IDEA Conf. Trade Show, IDEA Opening General Session, Jun. 23, 2003.

[38] N. Flatabø, G. Doorman, O. S. Grande, H. Randen, and I. Wangensteen, "Experience with the Nord Pool design and implementation," IEEE Trans. Power Syst., vol. 18, no. 2, pp. 541-547, May 2003.

[39] I. Wangensteen, A. Botterud, and N. Flatab $\varnothing$, "Power system planning and operation in international markets-Perspectives from the Nordic region and Europe," Proc. IEEE, vol. 93, no. 11, pp. 2049-2059, Nov. 2005 .

[40] S. D. Hanna and S. Lindamood, "An improved measure of risk aversion," Fin. Counsel. Plan., vol. 15, no. 2, pp. 27-38, 2004.

[41] Reliability Test System Task Force of the Application of Probability Methods Subcommitee, "The IEEE reliability test system-1996," IEEE Trans. Power Syst., vol. 14, no. 3, pp. 1010-1020, Aug. 1999.

[42] R. A. Collins, "The economics of electricity hedging and a proposed modification for the futures contract for electricity," IEEE Trans. Power Syst., vol. 17, no. 1, pp. 100-107, Feb. 2002.

[43] R. Brooks and A. A. El-Keib, "A life-cycle view of electricity futures contracts," J. Energy Fin. Develop., vol. 3, no. 2, pp. 171-183, 1998.

[44] J. S. Moulton, "California electricity futures: The NYMEX experience," Energy Econ., vol. 27, no. 1, pp. 181-194, Jan. 2005.

[45] J. Smith and B. Nau, "Valuing risky projects: Options pricing theory and decision analysis," Manage. Sci., vol. 41, no. 4, pp. 795-816, 1995.

[46] R. Fletcher, "A general quadratic programming algorithm," J. Inst. Math. Appl., vol. 7, pp. 76-91, 1971 .

[47] H. Levy, Introduction to Investment. Cincinnati, OH: South-Western College Publishing, 1996.

[48] Z. Bodie, A. Kane, and A. J. Marcus, Investments, 6th ed. New York: McGraw-Hill, 2005.

[49] R. H. Tütüncü and M. Koenig, "Robust asset allocation," Ann. Oper Res., vol. 132, pp. 157-187, 2004.

[50] C. Huang and R. Litzenberger, Foundations for Financial Economics. Englewood Cliffs, NJ: Prentice-Hall, 1988.

[51] G. G. Judge, R. C. Hill, W. E. Griffiths, H. Lutkepohl, and T. C. Lee, Introduction to the Theory and Practice of Econometrics. New York: Wiley, 1988.

[52] W. J.Conover, Practical Nonparametric Statistics. New York: Wiley, 1980.

Donghan Feng received the B.S. degree in electrical engineering from Zhejiang University, Hangzhou, China, in 2003. Currently, he is pursuing the Ph.D. degree from Zhejiang University.

In 2006, he spent two months as a visiting scholar at the University of Hong Kong. At present, he is also with the National Key Laboratory of Power Systems in Shenzhen and with the HKU and Tsinghua Shenzhen Power System Research Institute. His research interests are engineering and economic issues in electricity markets. 
Deqiang Gan received the Ph.D. degree in electrical engineering from Xian Jiaotong University, Xian, China, in 1994.

He has been with the faculty of Zhejiang University, Hangzhou, China, since 2002. He visited the University of Hong Kong in 2004 and 2005. He worked for ISO New England, Inc. from 1998 to 2002. He held research positions in Ibraki University, University of Central Florida, and Cornell University from 1994 to 1998. His research interests are power system stability and market operation.

Dr. Gan currently serves as an editor of European Transactions on Electric Power.

Jin Zhong (S'00-M'04) received the B.Sc. degree from Tsinghua University, Beijing, China, in 1995, the M.Sc. degree from China Electric Power Research Institute, Beijing, in 1998, and the Ph.D. degree from Chalmers University of Technology, Gothenburg, Sweden, in 2003.

At present, she is an Assistant Professor in the Department of Electrical and Electronic Engineering of the University of Hong Kong. Her areas of interest are electricity sector deregulation, ancillary service pricing, and power system planning.
Yixin Ni (SM'92) received the B. Eng., M. Eng., and Ph.D. degrees from Tsinghua University, Beijing, China.

She was a Professor and Director of the National Power System Laboratory with Tsinghua University and is currently with the University of Hong Kong. Her research interests are in power system stability and control, HVDC transmission, FACTS, and power market. 